\title{
HEPARIN-ASSOCIATED INTRATHORACIC PSEUDOTUMOR
}

\author{
L. C. H. John, MS, FRCS, and O. J. Lau, FRCS, London, United Kingdom
}

A 66-year-old man with a known history of chronic obstructive airway disease was admitted after development of a left pneumothorax. This was treated by the insertion of an apical intercostal tube connected to an underwater sealed drainage system. Chest radiography confirmed complete reexpansion of the left lung, and the drain was removed 48 hours later because no air leak was apparent. During this period, signs and symptoms of a left femoral arterial occlusion developed. This was managed by a femoral embolectomy and intravenous heparin administration. Three weeks after the removal of the intercostal tube, a routine chest radiograph revealed a cystic lesion in the left midlung field with an air-fluid level. Percutaneous needle biopsy of this lesion failed to provide a histologic diagnosis, and results of bronchoscopy were

From the Department of Cardiothoracic Surgery, The Brook Hospital, London, United Kingdom.

Received for publication Oct. 4, 1996; accepted for publication Dec. 9, 1996.

Address for reprints: L. C. H. John, Department of Cardiothoracic Surgery, St. Bartholomews Hospital, W. Smithfield, London EC1A 7BE, United Kingdom.

J Thorac Cardiovasc Surg 1997;113:1115-6

Copyright (C) 1997 by Mosby-Year Book, Inc.

$0022-5223 / 97 \$ 5.00+0 \quad \mathbf{1 2 / 5 4 / 7 9 7 8 9}$ unremarkable. An exploratory minithoracotomy was performed. At operation, a well-defined cystic mass measuring $4 \times 6 \mathrm{~cm}$ was found "embedded" within the oblique fissure between the left upper and lower lobes (Fig. 1). This mass was "shelled out" intact without difficulty. Postoperative recovery was uneventful, and the patient was discharged 1 week later. On pathologic examination, the lesion was found to be a fibrous-walled cyst containing a blood clot. The cyst wall consisted of organizing blood clot, and there was no evidence of malignancy.

Comment. The appearance on chest radiography of loculated pleural fluid collections may consist of opacities of varying sizes and shapes that can be difficult to distinguish from a pulmonary parenchymal process. ${ }^{1}$ Collections in atypical locations such as the interlobar fissure may be seen as "pseudotumors," which may normally be recognized by the biconvex lenticular shape and scissural position. ${ }^{2}$ In addition, fluid is often present elsewhere within the pleural space in cases of pseudotumor. In the case reported here, however, the appearance was consistent with a cystic lesion without evidence of a pleural collection elsewhere within the thorax. The differential diagnosis of an intrathoracic cystic lesion includes lung abscess, primary bronchial carcinoma, tuberculosis, and fungal disease. Although the period between an apparently normal chest radiograph after chest drain removal and the presence of the lesion 3 weeks later made malignancy an unlikely diagnosis, histologic diagnosis was

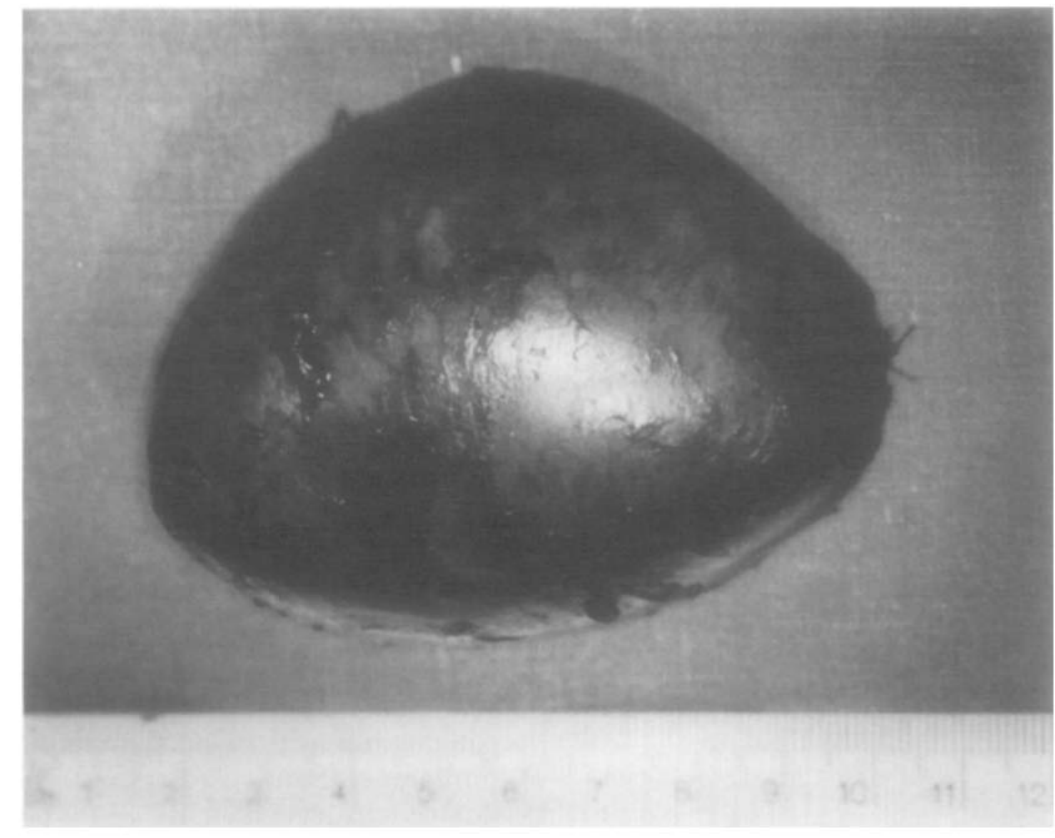

Fig. 1. Appearance of the cystic lesion after surgical removal. 
essential. In this case, needle biopsy was unsuccessful and an open thoracotomy was performed. An alternative approach used in many centers would have been a thoracoscopic excision, which might have resulted in a shorter hospitalization.

The precise etiology of the cystic lesion in this case is unknown. We speculate that hemorrhage and introduction of a small amount of air occurred on removal of the chest drain. The local collection of blood and air, combined with later organization of the blood clot, resulted in the formation of a cystic lesion. The reported incidence of hemorrhage occurring as a complication of the clinical use of heparin varies between $1 \%$ to $32 \% .^{3,4}$ Spontaneous hemorrhage at a number of sites, including intrathoracic hemorrhage, has been reported, ${ }^{5}$ and this was a likely contributory factor in this case.

Although the cystic lesion proved to be benign in this case, the normal features that aid differentiation of a "pseudotumor" from an actual tumor were absent. There was no pleural effusion elsewhere, the lesion was cystic, and there were no other medical conditions predisposing toward pleural fluid collection, such as cardiac failure or pleurisy. In such cases when intravenous heparin has been used, particularly in the presence of chest drains a hepa- rin-associated intrathoracic pseudotumor should be considered as part of the differential diagnosis. Nevertheless, a histologic diagnosis is essential to exclude malignancy, and an open thoracotomy or thoracoscopic resection is necessary if less invasive means are unsuccessful.

\section{REFERENCES}

1. Rusch VM. Pleural effusions: benign and malignant. In: Pearson FG, editor. Thoracic surgery. New York: Churchill Livingstone 1995:1003-16.

2. Henscke CI, Davis SD, Romano RH, Yankelowitz DF. Pleural effusions: pathogenesis, radiological evaluation, and therapy. J Thorac Imaging 1989;4:49-52.

3. Mant MJ, O'Brien BD, Thong KL, Hammong GW, Birtwhistle RV, Grace MG. Haemorrhagic complications of heparin therapy. Lancet 1977;1:1133-5.

4. Salzman EW, Deykin D, Shapiro RM, Rosenberg R. Management of heparin therapy, controlled prospective trial. N Engl J Med 1975;292:1047-50.

5. Holm HA, Abilgaard U, Kalvenes S. Heparin assays and bleeding complications in treatment of deep vein thrombosis with particular reference to retroperitoneal bleeding. Thromb Haemost 1985;53:278-81.

\title{
SINGLE LEUKOCYTE FILTER (PALL BC1B) FAILS IN MULTIDOSE COLD BLOOD CARDIOPLEGIA
}

\author{
Matthias Roth, MD, Erwin P. Bauer, MD, Oliver Reuthebuch, MD, and Wolf Peter Klövekorn, MD, \\ Bad Nauheim, Germany
}

Leukocyte depletion and its effect on reperfusion injury has been thoroughly investigated over the past several years. It has been shown to prevent myocardial edema, to decrease the incidence of ventricular arrhythmias, and to reduce free radical-mediated lung injury and cardiac reperfusion injury in animal models. Neutrophil granulocytes may cause myocardial stunning as a result of production of oxygen-derived free radicals, which may damage cell membranes, sarcoplasmic reticulum, and different enzymes. Furthermore, granulocytes can plug capillaries

From the Department of Thoracic and Cardiovascular Surgery, Kerckhoff Clinic, Max Planck Institute, Bad Nauheim, Germany.

Received for publication Nov. 18, 1996; accepted for publication Jan. 23, 1997.

Address for reprints: Matthias Roth, MD, Department of Thoracic and Cardiovascular Surgery, Kerckhoff Clinic, Max Planck Institute, Benekestr. 2-8, 61231 Bad Nauheim, Germany.

J Thorac Cardiovasc Surg 1997;113:1116-7

Copyright $\odot 1997$ by Mosby-Year Book, Inc.

$0022-5223 / 97 \$ 5.00+0 \quad \mathbf{1 2 / 5 4 / 8 0 7 3 9}$ during ischemia; after their degranulation, cell membranes may be damaged by different cell enzymes. Several reports describe leukocyte depletion in human beings. However, most results are not conclusive, especially with regard to filter efficiency. ${ }^{1-3}$ This study was undertaken to test the efficiency of the Pall BC1B leukocyte filter (Pall Biomedical Products Corp., East Hills, N.Y.) during multidose cold blood cardioplegia.

In a future study we intend to apply leukocyte-depleted blood during blood cardioplegic perfusion and during the first 5 minutes of reperfusion in selected patients with reduced left ventricular function (ejection fraction < $35 \%$ ) using a double-blind study protocol. Before doing this study, we wanted to test the efficiency of the Pall $\mathrm{BC} 1 \mathrm{~B}$ leukocyte filter for blood cardioplegia in $16 \mathrm{pa}$ tients.

Methods. Intermittent cold blood cardioplegic solution was used in all patients. Before aortic declamping the "hot shot" was infused during 4 minutes $\left(250 \mathrm{ml} \cdot \mathrm{min}^{-1}\right)$. All patients received a combination of antegrade $(50 \%)$ and retrograde $(50 \%)$ cardioplegic infusion. A single or a double leukocyte filter BC1B for blood cardioplegia (Pall Biomedical) was placed in the cardioplegia line before blood was mixed with cardioplegic solution. 